\title{
Powertrain mixture 2030 - influencing factors and outlook
}

\author{
Dr. Thomas Schlick, \\ Co-Authors: Dr. Wolfgang Bernhart, Markus Baum, \\ all Roland Berger $\mathrm{GmbH}$
}

Zum Zeitpunkt der Drucklegung lagen diese Unterlagen noch nicht vor. Wir bitten um Verständnis. 